\title{
Epidemiologic Characteristics of Patients Presenting with Head Injury due to Road Traffic Accident and Factors Associated with Outcome: Experience of a Tertiary Care Center in Northern Kerala
}

\author{
Mandaka Parambil Rajeev ${ }^{1}$ Vattaparambil Shinihas ${ }^{1} \quad$ Pankaj Singh Chauhan ${ }^{1}$ \\ ${ }^{1}$ Government Medical College, Kozhikode, Kerala, India \\ Address for correspondence Pankaj Singh Chauhan, MBBS, MS, MCh \\ (Neurosurgery), Government Medical College Kozhikode, Kozhikode \\ 673008, Kerala, India (e-mail: pankajschauhan2011@gmail.com).
}

Indian J Neurosurg 2019;8:39-46

\begin{abstract}
Background In India, most factors related to road traffic accident (RTA) causation and outcome go improperly documented, and database regarding RTA-related traumatic brain injury (TBI) seems inadequate. Two-wheeler drivers form the largest segment of people affected by RTA. The socioeconomic and neurologic burden, imposed by TBI due to RTAs (largely preventable), is overwhelmingly significant, especially for a developing country like India.

Materials and Methods Descriptive study involving patients, presenting to the casualty of Government Medical College, Kozhikode, Kerala, was performed, and various demographic features were analyzed. Usage of helmet and history of alcohol intake were also noted. Patients were evaluated according to their presenting Glasgow coma scale (GCS), investigated and either operated or managed conservatively, and their outcome was assessed with Glasgow outcome score (GOS) at 3 months.

Results Bike drivers formed the single largest proportion of RTA victims (53.7\%). Proportion of helmet users was $17.9 \%$, whereas $21.9 \%$ were found with history of alcohol intake. There was a consistent trend toward a favorable outcome in patients with no alcohol intake $(17.08 \%$ deaths compared with $34.07 \%$ patients with alcohol intake) and with helmet usage ( $14.55 \%$ compared with $22.18 \%$ in patients without helmet). However, the absolute contribution of these factors cannot be inferred.

Keywords

- road traffic accident

- helmet

- alcohol

Conclusion Various factors related to RTA need evaluation for pooling and compilation of data at regional and national levels. Mandatory helmet laws and strict implementation and provision of subsidized helmets (standard, full coverage) will go a long way in reducing the burden on limited health resources.
\end{abstract}

\section{Introduction}

It is often understated that accidents (particularly road traffic accident [RTA]) introduce the most sudden, unexpected, and disabling change in the victim's life, introducing lack of productivity and requiring treatment, supportive care, and, often, dependence for daily needs. The burden (economic

received July 29, 2018 accepted after revision October 3, 2018

published online

April 22, 2019 or otherwise) of neurologic disability is substantial to a developing country like India.

There has been a gradual increase in the number of personal vehicles (bikes, cars, etc.) on the road. Increasing number of motorcycles has been shown to be associated with increasing number of motorcycle crashes. Various factors associated with increased risk of accidents have been enumerated.
License terms @ 2019 Neurological Surgeons'
Society of India 
There seems to be a lack of national or regional database to calculate the incidence, magnitude, or burden of neurologic disability due to RTA. This study was undertaken to address the same concern.

\section{Method}

This descriptive study was undertaken in Government Medical College and Hospital, Kozhikode, Kerala (from January 1, 2017 to June 30, 2017). All patients coming to casualty were enrolled as per the following inclusion criteria: two-wheeler driving patients presenting after RTA and aged $\geq 13$ years (pediatric patients not enrolled), patients with radiologic abnormality on computed tomography (CT) of the brain, and patients with no radiologic abnormality on initial CT but with Glasgow coma scale $(\mathrm{GCS})<15$. Patients who were lost in follow-up or elected to go to other centers were excluded from the study $(n=83)$. Patients were classified into mild/moderate/severe traumatic brain injury (TBI) and managed accordingly. Data were collected according to structured proforma for history taking (including history of alcohol intake, helmet use, mode of injury), clinical examination (including GCS at admission, pupillary reaction/symmetry, hemodynamic status, level of consciousness), and radiologic evaluation (nature of intracranial injury and its evolution on CT, $\mathrm{X}$-ray to rule out associated fractures, etc.). Patients were managed either conservatively or with active intervention, on a case-to-case basis. Glasgow outcome score (GOS) was assessed at 3 months for all patients. Four groups of bike driver patients were compared: $\mathrm{SH}$-sober person with helmet, SF-sober person with free head (non-helmeted), $\mathrm{AH}$-person with alcohol intake with helmet, AF-person with alcohol with free head (non-helmeted).

Pediatric patients were not enrolled in the study, as pediatric emergencies are handled separately in our institution.

\section{Results}

In this study, patients presenting to our casualty (from January 1, 2017 to June 30, 2017) were included and followed up for a period of 3 months further. The distribution of patients according to various parameters studied is given along with.

In this study; of all RTA victims (1,145 patients) coming to our casualty in a period of 6 months, the minimum and maximum ages recorded were 13 and 91 years, respectively. The subset of victims most commonly affected in RTA (i.e., two-wheeler drivers, 615 in number, 53.7\%) was found to have age range from 13 to 72 years in our study (median age 30).

Maximum number of patients were found to be in their second and third decades, likely to be at their most productive years (24.9\% and $24.1 \%$, respectively). Other than 615 two-wheeler drivers (all males) with RTAs, the number of female two-wheeler drivers was 13 . None was found to have consumed alcohol. At time of crash, six wore helmets.
For uniformity, further analysis pertains only to male bike drivers. Helmet use was reported in $17.9 \%$ people, and the rest $82.1 \%$ were non-helmeted at time of crash. Alcohol was a factor in $21.9 \%$ of RTAs (all males).

\section{Analysis}

Patients coming to our casualty were found to have head injury from varied causes, in order being RTA (83.1\%), fall (15.2\%), assault ( $1 \%)$, and others $(0.7 \%$, e.g., coconut fall on head, collapse of roof on head). In a similar study, Agarwal et $\mathrm{al}^{1}$ in 2012 reported that RTA causes head injury in 56.3\% cases.

The GCS serves as a useful tool for rapid assessment, stratification, prognostication, serial assessment, interobserver communication, and easy reproducibility. GCS at presentation has been found to be a significant predictor of outcome. In this study, the distribution of patients with GCS score 3-8, 9-12, and $13-15$ was found to be 19,20 , and $61 \%$, respectively.

Patients were managed either with operation (25.4\%), conservatively (reason being either relatively mild injury (59\%), or diffuse nature of injury/very severe injury with poor prognosis (15.6\%). All patients were analyzed for outcome at 3 months by GOS. The overall mortality associated with GCS ranges of $3-8,9-12$, and $13-15$ was found to be $65.8,33.3$, and $2.7 \%$, respectively, in this study.

The distribution of injury types in this study included subarachnoid hemorrhage (SAH) (31.1\%), subdural hematoma (SDH) (22.4\%), epidural hematoma (EDH) (15.4\%), contusion (14.0\%), diffuse axonal injury (DAI) (3.9\%), depressed fracture (1.3\%), and mixed injury (11.9\%) (-Table 1). Overall mortality for all categories of bike driver patients included AF (34.4\%), $\mathrm{AH}(28.6 \%), \mathrm{SF}$ (18\%), and SH (13.6\%).

In a study by Tripathi et $\mathrm{al}^{2}$ in 2014 , the proportion of two-wheeler vehicle driver patients using helmet was found to be $16.5 \%$. The percentage of two-wheeler drivers using helmet was found to be $17.9 \%$, among patients presenting to our casualty. This may differ from the proportion of helmet usage in the general population. Reasons for not wearing helmet included (1) lack of helmet, (2) too short a trip to wear helmet, (3) inconvenience (heat, humidity), (4) lack of cosmesis, as per females, and (5) lack of helmet storing facility in the two-wheeler. Other and similar reasons for decreased helmet usage were elucidated by Wadhwaniya et al in $2015 .^{3}$

In this study, $21.9 \%$ of patients were found to have consumed alcohol at the time of crash. In the study by Tripathi et al in 2014, 22.5\% patients were found to have used alcohol.

A consistent relationship was noted between GCS at presentation and GOS at 3 months. Analysis was done to compare the GOS of each category of patients (i.e., patients with helmet, without helmet, patients with and without alcohol intake; see -Fig. 1, - Table 2). Overall, consistent trends toward favorable outcome were noted in patients without alcohol $34.07 \%$ deaths in patients with alcohol intake compared with $17.08 \%$ deaths in nonusers; see - Fig. 2 ).

The comparison of helmet users and nonusers revealed favorable trends in helmet users in mild to moderate 
Table 1 Distribution showing types of injuries in all categories of biker patients

\begin{tabular}{|c|c|c|c|c|c|c|c|c|c|c|}
\hline & \multicolumn{8}{|c|}{ Imaging } \\
\hline & & & Contusion & DAI & $\begin{array}{l}\text { Depressed } \\
\text { fracture }\end{array}$ & EDH & $\begin{array}{l}\text { Mixed } \\
\text { injury }\end{array}$ & SAH & SDH & Total \\
\hline \multirow[t]{4}{*}{$\begin{array}{l}\text { Type of } \\
\text { victim }\end{array}$} & $\mathrm{AF}$ & $\begin{array}{l}\text { Count } \\
\% \text { within type of victim }\end{array}$ & $\begin{array}{l}20 \\
15.6 \%\end{array}$ & $\begin{array}{l}6 \\
4.7 \%\end{array}$ & $\begin{array}{l}1 \\
0.8 \%\end{array}$ & $\begin{array}{l}21 \\
16.4 \%\end{array}$ & $\begin{array}{l}21 \\
16.4 \%\end{array}$ & $\begin{array}{l}25 \\
19.5 \%\end{array}$ & $\begin{array}{l}34 \\
26.6 \%\end{array}$ & $\begin{array}{l}128 \\
100 \%\end{array}$ \\
\hline & $\mathrm{AH}$ & $\begin{array}{l}\text { Count } \\
\% \text { within type of victim }\end{array}$ & $\begin{array}{l}0 \\
0 \%\end{array}$ & $\begin{array}{l}2 \\
28.6 \%\end{array}$ & $\begin{array}{l}0 \\
0 \%\end{array}$ & $\begin{array}{l}0 \\
0 \%\end{array}$ & $\begin{array}{l}1 \\
14.3 \%\end{array}$ & $\begin{array}{l}2 \\
28.6 \%\end{array}$ & $\begin{array}{l}2 \\
28.6 \%\end{array}$ & $\begin{array}{l}7 \\
100 \%\end{array}$ \\
\hline & SF & $\begin{array}{l}\text { Count } \\
\% \text { within type of victim }\end{array}$ & $\begin{array}{l}58 \\
15.4 \%\end{array}$ & $\begin{array}{l}11 \\
2.9 \%\end{array}$ & $\begin{array}{l}6 \\
1.6 \%\end{array}$ & $\begin{array}{l}74 \\
19.6 \%\end{array}$ & $\begin{array}{l}35 \\
9.3 \%\end{array}$ & $\begin{array}{l}95 \\
25.2 \%\end{array}$ & $\begin{array}{l}98 \\
26 \%\end{array}$ & $\begin{array}{l}377 \\
100 \%\end{array}$ \\
\hline & $\mathrm{SH}$ & $\begin{array}{l}\text { Count } \\
\% \text { within type of victim }\end{array}$ & $\begin{array}{l}8 \\
7.8 \%\end{array}$ & $\begin{array}{l}5 \\
4.9 \%\end{array}$ & $\begin{array}{l}1 \\
1 \%\end{array}$ & $\begin{array}{l}0 \\
0 \%\end{array}$ & $\begin{array}{l}16 \\
15.5 \%\end{array}$ & $\begin{array}{l}69 \\
67 \%\end{array}$ & $\begin{array}{l}4 \\
3.9 \%\end{array}$ & $\begin{array}{l}103 \\
100 \%\end{array}$ \\
\hline Total & & $\begin{array}{l}\text { Count } \\
\% \text { within type of victim }\end{array}$ & $\begin{array}{l}86 \\
14 \%\end{array}$ & $\begin{array}{l}24 \\
3.9 \%\end{array}$ & $\begin{array}{l}8 \\
1.3 \%\end{array}$ & $\begin{array}{l}95 \\
15.4 \%\end{array}$ & $\begin{array}{l}73 \\
11.9 \%\end{array}$ & $\begin{array}{l}191 \\
31.1 \%\end{array}$ & $\begin{array}{l}138 \\
22.4 \%\end{array}$ & $\begin{array}{l}615 \\
100 \%\end{array}$ \\
\hline
\end{tabular}

Abbreviations: AF, alcoholic patient, free head (non-helmeted); AH, alcoholic patient, helmet; DAl, diffuse axonal injury; EDH, epidural hematoma; GCS, Glasgow coma scale; GOS, Glasgow outcome score; SF, sober patient, free head (non-helmeted); SAH, subarachnoid hemorrhage; SDH, subdural hematoma; $\mathrm{SH}$, sober patient, helmet.

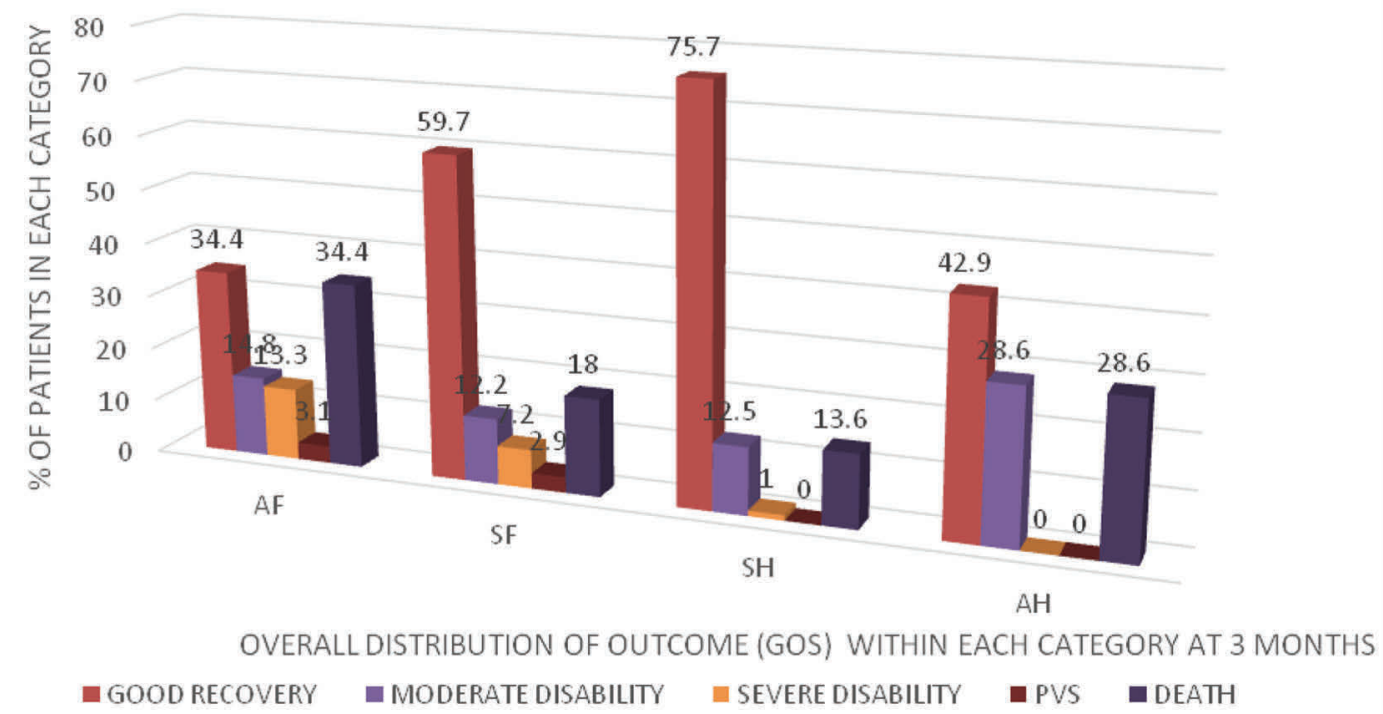

Fig. 1 Distribution of outcome (GOS) at 3 months. AF, alcoholic patient, free head (non-helmeted); AH, alcoholic patient, helmet; GCS, Glasgow coma scale; GOS, Glasgow outcome score; PVS, persistent vegetative state; SF, sober patient, free head (non-helmeted); SH, sober patient, helmet.

injury (GCS 13-15 and 9-12; see - Fig. 3). The proportion of overall deaths in patients with and without helmets was $14.55 \%$ and $22.18 \%$, respectively. In patients with severe head injury (GCS 3-8), the use of helmets fails to show a significant advantage in terms of outcome over nonuserspossibly because (1) the driver with helmet may be deemed to undergo much more severe impact to sustain the same degree of head injury as a nonuser and (2) with severe impact, a driver is likely to sustain other/multiple body injuries that contribute to mortality. It has been described previously, by Shibata et $\mathrm{al}^{4}$ that there is no added benefit from a helmet at crash speed $>50 \mathrm{~km} / \mathrm{h}$.

More studies may be called for to elaborate further on other parameters of significance in two-wheeler accidents, for example helmet make and type, blood alcohol levels at the time of crash, crash speed, factors related to vehicle type, and road conditions. This study may serve to highlight the need for regional and national databases in the form of structured format for RTA-related data and subsequent guidelines.

Glasgow outcome score for the groups with GCS 3-8, $9-12$, and $13-15$ is described according to the table along with.

\section{Discussion}

This study is an attempt to highlight various factors associated with RTAs: occurrence, management, and outcome. Factors associated with RTA may be categorized as related to either man, method, material, or machine. For example:

- Man-more than or equal to two pillion riders on two-wheeler, use of alcohol, lack of helmet, lack of skill/ license, unawareness of traffic rules 
Table 2 Distribution of all categories of biker patients according to GCS at presentation and GOS at 3 months

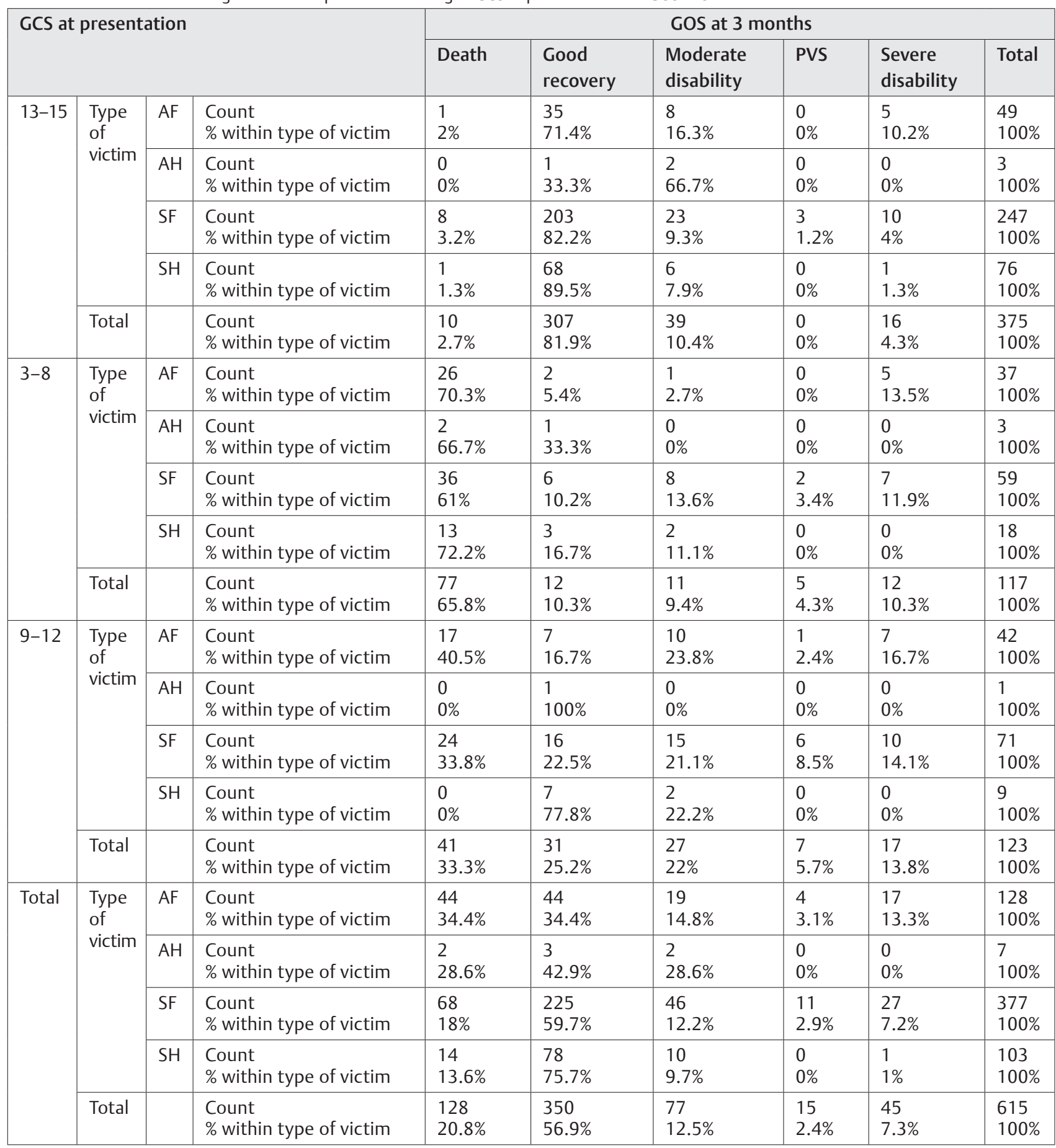

Abbreviations: AF, alcoholic patient, free head (non-helmeted); AH, alcoholic patient, helmet; GCS, Glasgow coma scale; GOS, Glasgow outcome score; PVS, persistent vegetative state; SF, sober patient, free head (non-helmeted); SH, sober patient, helmet.

- Method-rash driving/overspeed, ignoring traffic rules, using mobile while on road, wrong side driving, lack of heavy penalty

- Material-sloppy and rough road conditions, slippery surface, heavy rains, no checkpoints, roads with heavy traffic loads, encroachments on road sides, presence of animals on road, sudden turns, bad road conditions

- Machine-racing bikes, unfit vehicles on the road.
Perusing through published open access literature, an approximate estimate of the costs involved in TBI management can be made, as outlined by various studies. The estimated economic cost of TBI in the United States in 2010, including direct and indirect medical costs, was approximately $\$ 76.5$ billion (Centers for Disease Control and Prevention $[C D C]$ report); however, these data exist mostly for developed countries. Similar data for developing 


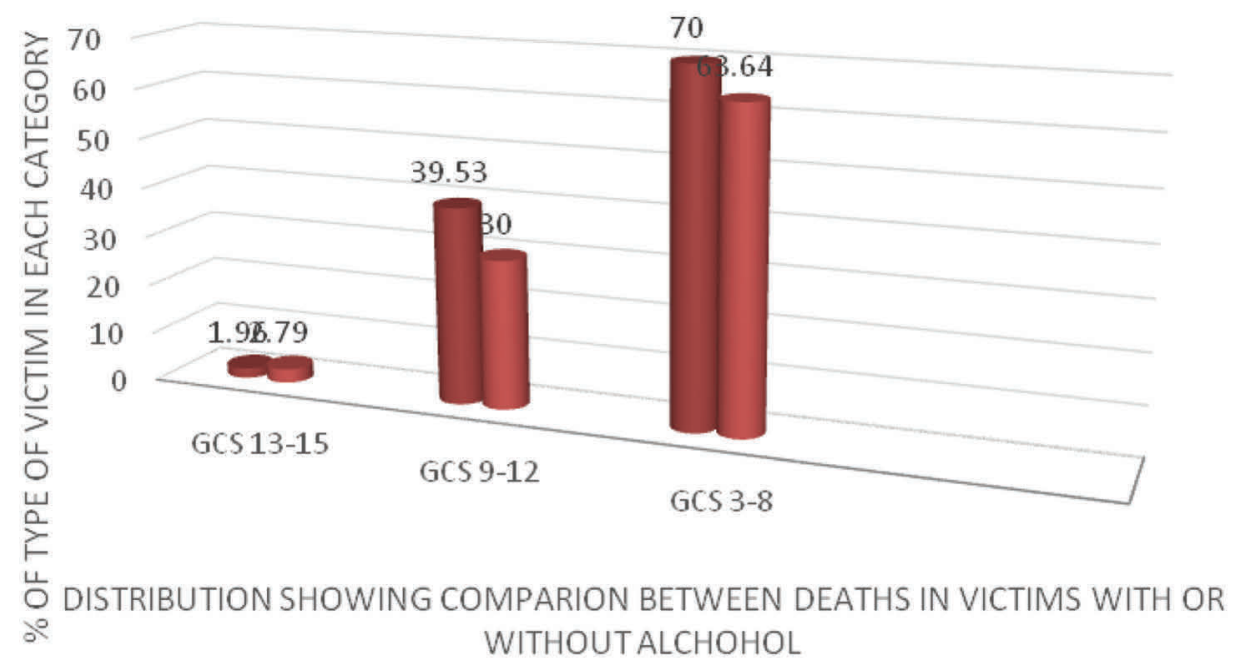

DEATHS IN ALCOHOLIC PATIENTS

DEATHS IN SOBER PATIENTS

Fig. 2 Deaths between alcohol users and nonusers. AF, alcoholic patient, free head (non-helmeted); AH, alcoholic patient, helmet; GCS, Glasgow coma scale; GOS, Glasgow outcome score; SF, sober patient, free head (non-helmeted); SH, sober patient, helmet.

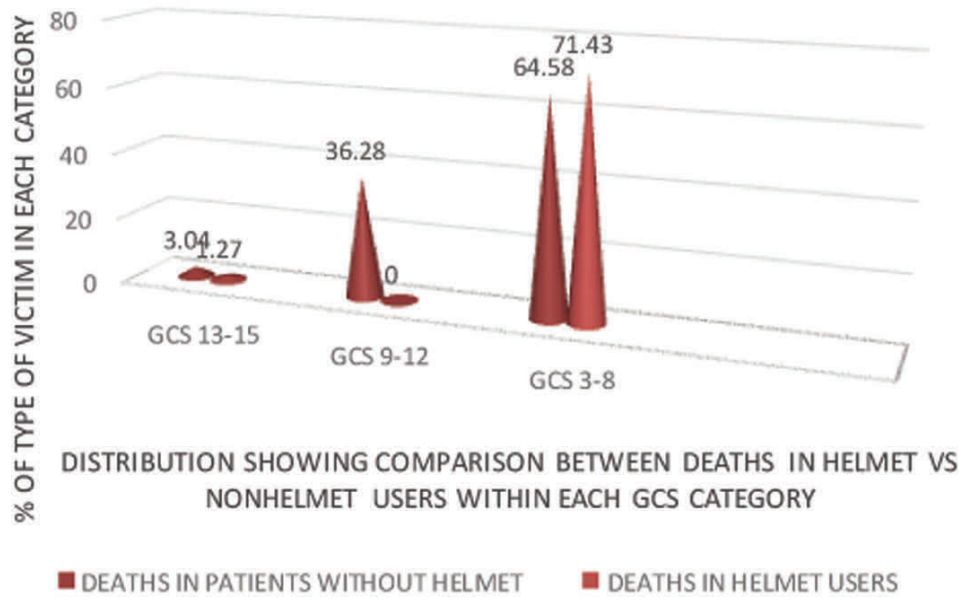

Fig. 3 Deaths between helmet users and nonusers. AF, alcoholic patient, free head (non-helmeted); AH, alcoholic patient, helmet; GCS, Glasgow coma scale; GOS, Glasgow outcome score; SF, sober patient, free head (non-helmeted); SH, sober patient, helmet.

countries, like India, are seemingly lacking. More studies such as this may contribute to forming a pool of data that can then be compiled to form a national policy.

According to an article by Das et al, ${ }^{5}$ only a fraction of the 1.4 million annual RTAs in India is recorded.

As per indianheadinjuryfoundation.org, in India 1 out of 6 trauma victims dies, whereas 1 out of 200 dies in the United States. According to the Ministry of Road Transport and Highways, Government of India (2007), 140,000 road accidents happened in 2007 with 40,612 people killed and 150,000 people injured. Corresponding figures for 2016 stand at 150,785 killed and another 494,624 injured in 480,652 road crashes (analysis of data by Ministry of Road Transport and Highways, 2016). ${ }^{6}$ India leads the world in fatalities due to road accidents. ${ }^{5}$ In India, the studies are performed either from traffic police records or from the hospitals. ${ }^{7-9}$ Coming mostly from metro cities and based on medicolegal records, the incidences of RTA may not be absolutely correct.7,10-12 In India, the incidence of head injury is steadily increasing with urbanization and increasing number of vehicles on the road. ${ }^{7,9}$

Among the victims of road traffic accidents, 70\% have head injury; among road accident deaths, head injury accounts for $70 \%$ of all deaths. ${ }^{8}$ Most deaths occur during first 72 hours. Recently, it has been noted that the number of fatal accidents has increased in India.

In India, $60 \%$ of all TBIs are caused by RTA. In this study, this contribution was $83 \%$. Alchohol involvement was $21.9 \%$ compared with the reported national average of 15 to $20 \%$. A 38 to $43 \%$ mortality rate is estimated in severe TBI. Most of 
those injured in RTA are considered vulnerable road userspedestrians, motorcyclists, four-wheel vehicle operators, and pedal cyclists.

Much has been discussed about the impact of helmet use and controversies surrounding mandatory helmet laws. It is self-evident that helmets provide some protection, even if the degree of that protection remains disputed. An excellent review comparing multiple studies may be had from the Journal of Trauma-Injury, Infection, and Critical Care, 2010. ${ }^{13}$ During a motorcycle crash, the rider is thrown off and the head hits an object. The forward motion of the head is stopped, but the brain continues to move until it strikes the inside of the skull. It then rebounds hitting the opposite side of the skull. The damage that results varies from minor head injuries to instantaneous death (depending on the amount of energy transferred in the crash). ${ }^{14}$

In India, different types of helmets available (e.g., full-face helmets, open face helmets, and half-head helmets) are used by people. Half-head helmets do not offer any protection in the event of a crash. ${ }^{15}$ Full-face helmets perform better in preventing head injuries over other helmet types, which may result from coverage of the entire head and the presence of a chin bar. ${ }^{16}$

As per the World Health organization (WHO), "wearing a helmet is the single most effective way of reducing head injuries and fatalities resulting from motorcycle crashes." Previous studies by the National Institute of Mental Health and Neurosciences (NIMHANS) in Bengaluru, India, have shown that in the event of nonusage of helmet, there exists a more than two times increased risk of death and severe brain injury; neurologic disability is increased by one and half times. The extent of hospitalization and health care costs are significantly higher for care of an injured person due to a crash. ${ }^{15,17}$ Helmet usage effectively reduces head injuries among motorcyclists; even so, a considerable proportion of motorcycle riders who wear helmets still sustain head injuries in crashes. ${ }^{18,19}$ It is not uncommon to observe a helmet getting detached at the time of a motorcycle crash. ${ }^{19,20}$ Head injuries seem to occur more frequently and are more severe for riders who wear a nonstandard helmet compared with those who wear a standard helmet. ${ }^{21}$ The use of borrowed and poorly fitting helmets is widely reported in many developing countries. More than one-third of riders use a helmet improperly, such as wearing it on the back of the head and leaving the chin strap loose. ${ }^{21,22}$ In this study, the proportion of helmet users was reported to be $17.9 \%$. Interestingly, the most common scenario was of a bystander claiming (in 32\% cases) an improperly strapped nonstandard helmet, flying off at the time of impact. We are prompted to suggest that data regarding helmet usage be collected mandatorily, by first attending ambulance drivers/ police wherever applicable. Helmets require replacement if it has been involved in a bike crash, dropped on a hard surface, or with visible signs of damage to the shell, foam, or straps, or every 3 to 5 years.

Alcohol makes a significant contribution to the morbidity and mortality of trauma patients, regardless of the type of injury suffered. ${ }^{23-26}$ Serum alcohol levels correlate closely with the extent of injury. ${ }^{27-29}$ In 2006, alcohol intoxication was involved in $32 \%$ of fatal motor vehicle crashes in the United States. ${ }^{30}$ Data from the United States reveal that 35 to $81 \%$ of the injured patients in TBI were found to be alcohol-intoxicated ${ }^{31,32}$ and $42 \%$ of the TBI patients were heavy drinkers before injury. ${ }^{32}$ Several laboratory studies conducted to investigate relationship between alcohol and TBI, using a variety of animal models, support the concept that alcohol worsens TBI. Tien et al in 2006 were the first to report significant differences in mortality in TBI patients depending on blood alcohol levels, ${ }^{33}$ wherein compared with the no alcohol reference group, the high alcohol group demonstrated worse survival rates. In 2008, O'Phelan et al reported similar findings in a more diverse population, including patients with substance abuse as well as alcohol intoxication. ${ }^{34}$ Regarding the influence of pre-TBI alcohol on neuropsychological testing, most researchers studying individuals with alcohol abuse and/or dependence prior to TBI have found inferior performance on neuropsychological/cognitive testing in alcohol-intoxicated patients with TBI. ${ }^{35-38}$ Alcohol consumption may have its effect in TBI by multiple mechanisms. From being a causative agent for increased risk-taking tendency to a decrease in responsible behavior (e.g., affecting carrying or wearing helmets), it impairs reaction time at the moment leading to the crash; impairs neurologic evaluation; and may be associated with chronic malnutrition, immunosuppression, or coagulopathy.

Analysis from this study shows that most accidents take place between 7 p.m. and 1 a.m. In a similar study from Nigeria by Onwuchekwa and Echem, maximum frequency of accident and emergency department visits was found during night duty shift. ${ }^{39}$ This may be contributed to by poor visibility, fatigue after a hectic day at work, indulging in overspeeding due to relatively less traffic, and hurrying to reach destination. Kerala police website identifies certain areas in Kozhikode (e.g., Nadakkav, Erhanipalam, Thondayad, etc.) as having a particularly higher frequency of RTAs. Total number of RTAs in Kerala in 2016 was projected as 39,420, leading to 44,108 victims. The median average length of stay in intensive care unit (ICU) and hospital in our setting were 12 and 32 days, respectively.

Regarding the economic and social cost of road traffic crashes in India, an excellent review of the methodology and limitations in assessing the cost analysis of RTA by Dinesh Mohan ${ }^{40}$ suggests the cost of road crash injuries as close to 3\% of gross domestic product (GDP). For 2016, this approximates to 55,000 crores or 8.2 billion. Similar figures are echoed by the Ministry of Road Transport and Highways, Government of India. These estimates indicate the magnitude of priority that the preventive aspect of RTA-related TBI entails.

\section{Limitations of the Study}

The patient sample may not be reflective of the total RTA-affected population segment. The reasons for this may be preference of patients to reach the hospital nearest to the site of accident. This study has very fewer number of car driving victims possibly reflecting an upper class socioeconomic 
preference for private hospitals. At present, there seems to be no mandatory interdepartmental collaboration and between various hospitals to share data or regular audit regarding RTA incidence and demographic factors. The available printed format of history taking does not reflect various risk factors responsible for RTA. A detailed comparison between severity of injury and various helmet types could not be done in this study, due to relative paucity of adequate numbers of patients in each category.

\section{Conclusion}

This study highlights the needs for centralized database for national and regional RTA-related neurologic disability assessment. In this study, almost 10 to $15 \%$ cases were lost to follow-up. This was partly due to patients not reporting to going to other centers but also due to lack of computerization, different OPD serial number at subsequent visits, and lack of provisions or regulations requiring pooling of data in chronological manner.

Mandatory collaboration between various registries (about the incidence and factors involved in the accident) should be instituted to arrive at correct regional figures.

Multipronged approach to the effective implementation of helmet laws is required, more so because it targets the most vulnerable segment affected in RTAs; hence, it is likely to cause the most significant improvement in TBI outcome, as a single measure. Regular educational outreach programs, distribution of standard ISO helmets with chin strap at subsidized prices at institutions or organizations, and strict punitive action against offenders may go a long way in achieving reduction in TBI-related morbidity and loss of productivity. The assessed cost of transport, treatment, ventilator, and ICU and hospital stay may well prove less than the cost of preventive helmet distribution.

\section{References}

1 Agrawal A, Galwankar S, Kapil V, et al. Epidemiology and clinical characteristics of traumatic brain injuries in a rural setting in Maharashtra, India. 2007-2009. Int J Crit Illn Inj Sci 2012;2(3):167-171

2 Tripathi M, Tewari MK, Mukherjee K, Mathuriya SN. Profile of patients with head injury among vehicular accidents: an experience from a tertiary care centre of India. Neurol India 2014;62(6):610-617

3 Wadhwaniya S, Gupta S, Tetali S, Josyula LK, Gururaj G, Hyder AA. The validity of self-reported helmet use among motorcyclists in India. WHO South-East Asia J Public Health 2015;4(1):38-44

4 Shibata A, Fukuda K. Risk factors of fatality in motor vehicle traffic accidents. Accid Anal Prev 1994;26(3):391-397

5 Das A, Botticello AL, Wylie GR, Radhakrishnan K. Neurologic disability: a hidden epidemic for India. Neurology 2012;79 (21):2146-2147

6 Road accidents in India-2016. New Delhi, Delhi: Ministry of Road Transport \& Highways Transport Research Wing; 2016

7 Report of Road Safety Cell: Ministry of Transport. Govt. of India; 1993
8 Ramamurthi B. Road accidents, epidemiology and prevention. Neurol India 1995;43(Suppl):9-15

9 Mahapatra AK. Current management of head injury. Neuroscience Today 1997;1:197-204

10 Fife D, Faich G, Hollinshead W, Boynton W. Incidence and outcome of hospital-treated head injury in Rhode Island. Am J Public Health 1986;76(7):773-778

11 Editorial: Head injuries: a neglected field in India. National Medical Journal 1991;4:44-53

12 Sambasivan M. Epidemiology of neurotraumic. Neurol India 1993;3(Suppl):41

13 MacLeod J, DiGiacomo JC, Tinkoff G. An evidence-based review: helmet efficacy to reduce head injury and mortality: EAST practice management guidelines. J Trauma 2010;69(5):1101-1111

14 Yadukul S, Devadass PK, Gururaj G. Role of helmet in preventing head injury among two wheeler occupants in fatal road traffic injuries. Indian Journal of Forensic Medicine \& Toxicology 2016 Jan-Jun;10(1):6-10

15 Gururaj G. Head Injuries \& Helmets: Helmet Legislation and Enforcement in Karnataka and India. Bangalore, India: National Institute of Mental Health \& Neuro Sciences; 2005

16 Yu W-Y, Chen C-Y, Chiu W-T, Lin M-R. Effectiveness of different types of motorcycle helmets and effects of their improper use on head injuries. Int J Epidemiol 2011;40(3):794-803

17 Helmets: A Road Safety Manual for Decision Makers and Practitioners. Geneva, Switzerland: World Health Organization; 2006

18 Sarkar S, Peek C, Kraus JF. Fatal injuries in motorcycle riders according to helmet use. J Trauma 1995;38(2):242-245

19 Richter M, Otte D, Lehmann U, et al. Head injury mechanisms in helmet-protected motorcyclists: prospective multicenter study. J Trauma 2001;51(5):949-958

20 Richards PG. Detachment of crash helmets during motorcycle accidents. Br Med J (Clin Res Ed) 1984;288(6419):758

21 Peek-Asa C, McArthur DL, Kraus JF. The prevalence of non-standard helmet use and head injuries among motorcycle riders. Accid Anal Prev 1999;31(3):229-233

22 Conrad P, Bradshaw YS, Lamsudin R, Kasniyah N, Costello C. Helmets, injuries and cultural definitions: motorcycle injury in urban Indonesia. Accid Anal Prev 1996;28(2):193-200

23 NHTSA. The Economic Impact of Motor Vehicle Crashes. Washington, DC: Dept of Transportation (US), National Highway Traffic Safety Administration (NHTSA); 2000. http:// www.dot.gov/safety.html

24 The Economic Impact of Motor Vehicle Crashes 2000. Washington, DC: Dept of Transportation, National Highway Traffic Safety Administration; 2000. http://www-nrd.nhtsa. dot.gov/Pubs/

25 U.S. Dept. of Transportation, National Highway Traffic Safety Division. Traffic Safety Facts 1996: Alcohol. Washington, DC: National Center for Statistics \& Analysis, Research \& Development; 1997

26 Stewart RM, Myers JG, Dent DL, et al. Seven hundred fifty-three consecutive deaths in a level I trauma center: the argument for injury prevention. J Trauma 2003;54(1):66-70, discussion 70-71

27 Fabbri A, Marchesini G, Morselli-Labate AM, et al. Positive blood alcohol concentration and road accidents. A prospective study in an Italian emergency department. Emerg Med J 2002;19(3):210-214

28 Pories SE, Gamelli RL, Vacek P, Goodwin G, Shinozaki T, Harris F. Intoxication and injury. J Trauma 1992;32(1):60-64

29 Waller PF, Stewart JR, Hansen AR, Stutts JC, Popkin CL, Rodgman EA. The potentiating effects of alcohol on driver injury. JAMA 1986;256(11):1461-1466 
30 National Highway Traffic Safety Administration. Traffic Safety Facts. 2006

31 Corrigan JD. Substance abuse as a mediating factor in outcome from traumatic brain injury. Arch Phys Med Rehabil 1995;76(4):302-309

32 Kolakowsky-Hayner SA, Gourley EV III, Kreutzer JS, Marwitz JH, Cifu DX, Mckinley WO. Pre-injury substance abuse among persons with brain injury and persons with spinal cord injury. Brain Inj 1999;13(8):571-581

33 Tien HC, Tremblay LN, Rizoli SB, et al. Association between alcohol and mortality in patients with severe traumatic head injury. Arch Surg 2006;141(12):1185-1191, discussion 1192

34 O'Phelan K, McArthur DL, Chang CW, Green D, Hovda DA. The impact of substance abuse on mortality in patients with severe traumatic brain injury. J Trauma 2008;65(3):674-677

35 Jorge RE, Starkstein SE, Arndt S, Moser D, Crespo-Facorro B, Robinson RG. Alcohol misuse and mood disorders following traumatic brain injury. Arch Gen Psychiatry 2005;62(7):742-749
36 Bombardier $\mathrm{CH}$, Thurber CA. Blood alcohol level and early cognitive status after traumatic brain injury. Brain Inj 1998;12(9):725-734

37 Kelly MP, Johnson CT, Knoller N, Drubach DA, Winslow MM. Substance abuse, traumatic brain injury and neuropsychological outcome. Brain Inj 1997;11(6):391-402

38 Tate PS, Freed DM, Bombardier CH, Harter SL, Brinkman S. Traumatic brain injury: influence of blood alcohol level on post-acute cognitive function. Brain Inj 1999;13(10):767-784

39 Onwuchekwa RC, Echem RC. An epidemiologic study of traumatic head injuries in the emergency department of a tertiary health institution. J Med Trop 2018;20:24-29

40 Proceedings First Safe Community Conference on Cost of Injury. Viborg, Denmark, October 2002:33-38 